\title{
Benchmark study using a multi-scale, multi-methodological approach for the petrophysical characterization of reservoir sandstones
}

\section{Supplementary material}

Peleg Haruzi ${ }^{1,2}$, Regina Katsman ${ }^{1}$, Matthias Halisch ${ }^{3}$, Nicolas Waldmann ${ }^{1}$, and Baruch Spiro ${ }^{1,4}$

Correspondence to: Regina Katsman (rkatsman@univ.haifa.ac.il)

Matthias Halisch (Matthias.Halisch@leibniz-liag.de)

${ }^{1}$ The Dr. Moses Strauss Department of Marine Geosciences, Faculty of Natural Sciences, The University of Haifa, Haifa, Mount Carmel 3498838, Israel

2 Agrosphere Institute, IBG-3, Institute of Bio- and Geosciences, Forschungszentrum Jülich GmbH, Germany

${ }^{3}$ Leibniz Institute for Applied Geophysics, Dept. 5 - Petrophysics \& Borehole Geophysics, Stilleweg 2, D-30655 Hannover, Germany

4 Department of Earth Sciences, Natural History Museum, Cromwell Road, London SW7 5BD, UK 
This supplementary material contains a link to a data repository with datasets related to the samples S1, S2, S3 explored in the paper:

https://doi.org/10.1594/PANGAEA.907552

\section{Description:}

The datasets contain:

1. One file with data for grain size analysis: grain_size_S1_S2_S3.xls. It includes data for samples $\mathrm{S} 1, \mathrm{~S} 2, \mathrm{~S} 3$ in 3 tabs.

2. Three files for mercury intrusion porosimetry: MIP_S1.TXT, MIP_S2.TXT, MIP_S3.TXT.

3. Three files for XRD analysis: XRD_S1.doc, XRD_S2.doc, XRD_S3.doc.

4. Data for porosity and permeability measurements for three samples:

por_perm_S1_S2_S3.xlsx.

5. Three micro micro-CT image stacks for S1, S2, S3: S1_CT.zip, S2_CT.zip, S3_CT.zip 